\title{
QUALIDADE FÍSICA E FISIOLÓGICA DE SEMENTE DE SOJA COLHIDA COM SISTEMA DE TRILHA AXIAL SOB DIFERENTES VELOCIDADES DE OPERAÇÃO E ROTAÇÕES DO CILINDRO TRILHADOR
}

\section{BRUNO G. T. L. VIEIRA ${ }^{1}$, ROUVERSON P. DA SILVA ${ }^{2}$, ROBERVAL D. VIEIRA ${ }^{3}$}

RESUMO: A colheita mecanizada é ferramenta fundamental no processo produtivo das grandes culturas; se não for realizada adequadamente, poderá resultar em danos mecânicos severos às sementes, acarretando, prejuízos significativos na colheita, particularmente devido à redução da qualidade. Visando a avaliar os danos causados na colheita mecanizada de soja, o presente trabalho teve como objetivo estudar o efeito do sistema de trilha axial sobre a percentagem de bandinhas, impurezas e sementes quebradas de soja cv. M-Soy 8001, em função da velocidade de trabalho e rotação do cilindro trilhador. O delineamento experimental utilizado foi o inteiramente casualizado, em parcelas subdivididas, avaliando-se duas rotações do cilindro trilhador (400 e $500 \mathrm{rpm}$ ) e três velocidades de operação $\left(3,5 ; 4,5\right.$ e $\left.5,5 \mathrm{~km} \mathrm{~h}^{-1}\right)$, com três repetições. Os resultados obtidos indicam que as combinações de velocidade de operação e rotações do cilindro de trilha avaliadas não afetam as variáveis vigor, impurezas, bandinha, emergência em areia e índice de velocidade de germinação e que o aumento da rotação de 400 para 500 rpm ocasiona o aumento de sementes quebradas.

PALAVRAS-CHAVE: perdas na colheita, vigor, qualidade.

\section{PHYSICAL AND PHYSIOLOGICAL SEED QUALITY OF SOYBEAN HARVESTED WITH AXIAL SYSTEM TRACK UNDER DIFFERENT SPEEDS OPERATION AND TRACKING CYLINDER ROTATIONS}

\begin{abstract}
The mechanical harvest is an important tool in the productive process of grain crops. For the soybean crop, if not used appropriately, it can result in severe mechanical damages to the seed, caring out significant damages to the crop, especially on seed quality. In order to evaluate the damages caused by mechanical soybean harvesting, the purpose of the present research was to study the effect of the system of axial trail on the bands percentage, the amount of MOG (other material different from the grain) and broken seeds of soybean (cv. M-soy 8001), in function of the speed of work and rotation of the threshing cylinder. The experimental design was completely randomized in split plot, being evaluated two threshing cylinder rotations (400 and $500 \mathrm{rpm}$ ), three operation speeds $\left(3.5 ; 4.5\right.$ and $\left.5.5 \mathrm{~km} \mathrm{~h}^{-1}\right)$ with three replications. The results obtained showed that the combination of speed operations and rotation of threshing cylinder evaluated, did not affect the seed vigor, impurity, bands, sand emergence and germination speed index and that increasing the rotation of the 400 to $500 \mathrm{rpm}$ broken seeds were bigger.
\end{abstract}

KEYWORDS: harvesting losses, vigor, quality.

\section{INTRODUÇÃO}

A produção de sementes de soja de alta qualidade requer cuidado especial, pois a desatenção durante as diversas fases de sua obtenção pode acarretar recusa de lotes ou mesmo de toda a produção (TOLEDO \& MARCOS FILHO, 1977).

O processo de colheita constitui-se em uma importante etapa no processo produtivo da soja, principalmente pelos riscos a que está sujeita a lavoura destinada à produção de sementes. Para

\footnotetext{
${ }^{1}$ Biólogo, Pós-Graduando, Departamento de Produção Vegetal, UNESP - Jaboticabal, vieirabgtl@ gmail.com

${ }^{2}$ Eng ${ }^{\mathrm{O}}$ Agrí́cola, Prof. Dr., Departamento de Engenharia Rural, UNESP - Jaboticabal - SP.

${ }^{3}$ Eng ${ }^{0}$ Agrônomo, Prof. Dr., Departamento de Produção Vegetal, UNESP - Jaboticabal - SP.

Recebido pelo Conselho Editorial em: 3-1-2006

Aprovado pelo Conselho Editorial em: 12-5-2006
} 
evitar perdas na qualidade do produto, a colheita deve ser iniciada tão logo a soja atinja o estádio R8, correspondente ao ponto de maturação fisiológica (EMBRAPA, 2005).

Segundo MOORE (1960, 1962a, 1973), os danos mecânicos causados por percevejos, por secas e por altas temperaturas, secagem, geadas e pela deterioração por umidade afetam a qualidade da semente de soja e, conforme EMBRAPA (2005), interferem na colheita, acarretando perdas significativas.

Os mecanismos de trilha normalmente transmitem impactos agressivos sobre as plantas, principalmente os de alimentação tangencial, pois o sistema envolve ações simultâneas de impacto, de compressão e atrito sobre as sementes, que são levadas a passar entre o cilindro e o côncavo durante a colheita (COSTA et al., 2003).

Dentre os diversos fatores que prejudicam a colheita, o preparo inadequado do solo pode causar prejuízos devido a desníveis no terreno, que provocam oscilações na barra de corte da colhedora, fazendo com que ocorra corte em altura desuniforme e que muitas vagens sejam cortadas ao meio e que outras deixem de ser colhidas.

A umidade inadequada é outro grande problema, sendo recomendada a colheita da soja com teor de água entre 13 e 15\%, o que minimiza os problemas de danos mecânicos e perdas na colheita. Sementes colhidas com teor de água superior a 15\% estão sujeitas a maior incidência de danos mecânicos latentes e, quando colhidas com teor abaixo de $12 \%$, estão suscetíveis ao dano mecânico imediato, ou seja, à quebra (EMBRAPA, 2005).

Para CORREIA \& REZENDE (1994), a presença de plantas invasoras na cultura causa problemas que se refletem em perdas na qualidade do produto, no rendimento e até mesmo na inviabilização da colheita. Entretanto, a ocorrência dessas plantas faz com que a umidade permaneça alta por muito tempo, prejudicando o bom funcionamento da colhedora e exigindo maior rotação do cilindro de trilha, resultando em maior dano mecânico às sementes (EMBRAPA, 2005).

O presente trabalho teve como objetivo avaliar as perdas qualitativas na colheita mecanizada de soja, colhida com sistema de trilha axial, sob duas rotações do cilindro trilhador e três velocidades de deslocamento.

\section{MATERIAL E MÉTODOS}

O trabalho foi conduzido na Fazenda Cossisa, localizada em Uberlândia - MG (18 ${ }^{\circ} 5^{\prime}$ latitude sul, $48^{\circ} 17^{\prime}$ ' longitude oeste e altitude de $940 \mathrm{~m}$ ) e no Laboratório de Análise de Sementes, do Departamento de Produção Vegetal, da UNESP - Jaboticabal - SP.

Foi utilizada a colhedora Case, modelo 2366, ano de fabricação 2000, operando com velocidades de deslocamento de 3,5; 4,5 e 5,5 $\mathrm{km} \mathrm{h}^{-1}$ (V1, V2 e V3, respectivamente) e rotações do cilindro de trilha de 400 e $500 \mathrm{rpm}$ (R1 e R2). A colheita ocorreu em abril de 2005, sendo utilizada a cultivar M-Soy 8001, com teor médio de água de $12 \%$, obtido por meio de aparelho digital portátil, no momento da colheita.

O delineamento experimental utilizado foi o inteiramente casualizado, em parcelas subdivididas, com duas rotações de cilindro de trilha e três velocidades de operação, com três repetições, analisados com programa computacional STAT (Tukey a 5\% de probabilidade). Os resultados, expressos em percentagem, foram previamente transformados em arco-seno da raiz quadrada de $(\mathrm{x}+0,5) / 100$. Na Tabela 1 , são apresentadas as médias relativas aos dados originais.

Durante a colheita, pequenas amostras de sementes foram coletadas do elevador de descarga dentro do tanque graneleiro, e, após a coleta, essas sementes foram homogeneizadas e acondicionadas em sacos de papel Kraft, discriminando-se os tratamentos das mesmas e posteriormente armazenando-as em câmara fria a $10{ }^{\circ} \mathrm{C}$. 
Para a determinação de sementes quebradas, bandinhas (sementes partidas, divididas em seus cotilédones) e impurezas, foi utilizada a peneira de crivo oblongo $\mathrm{n}^{\mathrm{o}}$ 11/64 x 3/4. A avaliação de sementes quebradas, em cada amostra, foi obtida pela razão entre a massa das mesmas e a massa total da respectiva amostra.

Para a determinação da qualidade, as sementes foram submetidas aos testes de germinação em substrato de papel e areia (BRASIL, 1992), calculando-se o índice de velocidade de germinação conforme a fórmula proposta por MAGUIRE (1962) e ao teste de tetrazólio (FRANÇA NETO et al., 1999).

O teste de germinação foi realizado com 200 sementes (quatro subamostras de 50 sementes) que foram semeadas em rolos de papel tipo germitest, com quantidade de água equivalente a 2,5 vezes a sua massa seca, e colocadas em germinador regulado a $25^{\circ} \mathrm{C}$, por cinco dias. A contagem das plântulas normais foi realizada ao quinto dia após a semeadura (BRASIL, 1992).

Para o teste de emergência em areia, também foram semeadas 200 sementes (quatro subamostras de 50 sementes) em caixas plásticas, com aproximadamente $3,5 \mathrm{~kg}$ de areia. A contagem das plântulas normais emergidas foi realizada ao quinto dia após a semeadura (BRASIL, 1992).

Para a determinação do índice de velocidade de germinação, foram realizadas contagens diárias, computando-se o número de sementes germinadas (com emergência total dos cotilédones), até atingir a estabilização, quando foi feito seu cálculo, conforme fórmula proposta por MAGUIRE (1962), citada por NAKAGAWA (1999).

O teste de tetrazólio foi empregado para averiguar o vigor, a viabilidade e os danos mecânicos causados pelo mecanismo de trilha, conforme metodologia descrita por FRANÇA NETO et al. (1999). Na condução do referido teste, foram retiradas 100 sementes de cada amostra, divididas em duas subamostras de 50 sementes, as quais foram pré-condicionadas em papel germitest umedecido, com quantidade de água equivalente a 2,5 vezes a sua massa, durante $16 \mathrm{~h}$, em temperatura ambiente. Em seguida, as sementes foram depositadas em copos plásticos de $50 \mathrm{~mL}$ de capacidade, sendo adicionada solução na concentração de 0,075\% de 2,3,5-trifenilcloreto-de-tetrazólio, e colocadas no escuro, em estufa, com temperatura de $40{ }^{\circ} \mathrm{C}$, por até três horas, sendo posteriormente lavadas em água corrente e analisadas individualmente.

\section{RESULTADOS E DISCUSSÃO}

As análises estatísticas para os testes de vigor, impurezas, bandinha, emergência em areia e índice de velocidade de germinação não apresentaram diferenças estatísticas para os fatores velocidade e rotação, bem como para a interação entre eles (Tabela 1). Como a variação de velocidades de 3,5 a $5,5 \mathrm{~km} \mathrm{~h}^{-1}$ e rotações do cilindro de trilha de 400 a $500 \mathrm{rpm}$ se encontravam em faixa ótima de operação, não causaram danos significativos, concordando com as afirmações de COSTA et al. (2001) e HERBEK \& BITZER (1997). Esses autores afirmam também que as perdas são menores para combinações de velocidade e rotação dentro dessa faixa de operação. Os coeficientes de variação encontrados foram adequados para todas as variáveis analisadas.

O fator velocidade de deslocamento e a interação entre velocidade e rotação do cilindro não afetaram a percentagem de sementes quebradas (Tabela 1); entretanto, a rotação do cilindro trilhador afetou significativamente essa variável. Observa-se, pela Tabela 1, que o aumento da rotação de 400 para $500 \mathrm{rpm}$ proporcionou maior percentagem de sementes quebradas. Segundo COSTA et al. (2002), a colheita realizada com maiores rotações do cilindro de trilha resultam em níveis mais acentuados de danos mecânicos, sementes quebradas e ruptura de tegumento, principalmente quando associado a maiores índices de deterioração por umidade, lesões por percevejos e teor de água das sementes/grãos no momento da colheita. 
TABELA 1. Síntese da análise de variância dos dados referentes à percentagem de sementes quebradas, tetrazólio (TZ 1-3), impurezas, bandinhas, emergência em areia e análise do índice de velocidade de germinação (IVG) de semente de soja colhida sob sistema de trilha axial. ${ }^{(1)}$

\begin{tabular}{|c|c|c|c|c|c|c|}
\hline Tratamentos & $\begin{array}{l}\text { Sementes } \\
\text { Quebradas }\end{array}$ & $\begin{array}{c}\text { Vigor } \\
(\mathrm{Tz}(1-3))\end{array}$ & Impurezas & Bandinhas & $\begin{array}{c}\text { Emergência } \\
\text { em Areia }\end{array}$ & IVG \\
\hline \multicolumn{7}{|c|}{$\%$} \\
\hline \multicolumn{7}{|l|}{ Velocidade (V) } \\
\hline $\mathrm{V} 1$ & $6,8 \mathrm{a}$ & $92,3 \mathrm{a}$ & $6,0 \mathrm{a}$ & $10,5 \mathrm{a}$ & $47,0 \mathrm{a}$ & $11,6 \mathrm{a}$ \\
\hline V2 & $8,5 \mathrm{a}$ & $82,3 \mathrm{a}$ & $7,1 \mathrm{a}$ & $11,8 \mathrm{a}$ & $73,9 \mathrm{a}$ & $10,9 \mathrm{a}$ \\
\hline V3 & $7,9 \mathrm{a}$ & $92,6 \mathrm{a}$ & $6,0 \mathrm{a}$ & $11,1 \mathrm{a}$ & $75,0 \mathrm{a}$ & $11,1 \mathrm{a}$ \\
\hline \multicolumn{7}{|l|}{ Rotação (R) } \\
\hline $\mathrm{R} 1$ & $6,8 \mathrm{~b}$ & $87,7 \mathrm{a}$ & $7,3 \mathrm{a}$ & $10,2 \mathrm{a}$ & $67,3 \mathrm{a}$ & $11,3 \mathrm{a}$ \\
\hline $\mathrm{R} 2$ & $8,7 \mathrm{a}$ & $91,1 \mathrm{a}$ & $5,5 \mathrm{a}$ & $12,2 \mathrm{a}$ & $64,1 \mathrm{a}$ & $11,1 \mathrm{a}$ \\
\hline \multicolumn{7}{|l|}{ Teste F } \\
\hline $\mathrm{V}$ & $0,85^{\mathrm{NS}}$ & $0,69^{\mathrm{NS}}$ & $0,38^{\mathrm{NS}}$ & $0,32^{\mathrm{NS}}$ & $4,80^{\mathrm{NS}}$ & $3,73^{\mathrm{NS}}$ \\
\hline $\mathrm{R}$ & $14,76 *$ & $0,26^{\mathrm{NS}}$ & $3,30^{\mathrm{NS}}$ & $4,29^{\mathrm{NS}}$ & $0,04^{\mathrm{NS}}$ & $1,04^{\mathrm{NS}}$ \\
\hline $\mathrm{VxR}$ & $3,79^{\mathrm{NS}}$ & $0,86^{\mathrm{NS}}$ & $3,20^{\mathrm{NS}}$ & $1,55^{\mathrm{NS}}$ & $0,01^{\mathrm{NS}}$ & $4,09^{\mathrm{NS}}$ \\
\hline \multicolumn{7}{|l|}{ C.V.(\%) } \\
\hline Parcelas & 14,86 & 21,29 & 19,59 & 13,09 & 19,48 & 1,90 \\
\hline Subparcelas & 6,84 & 18,91 & 16,21 & 9,43 & 35,54 & 2,41 \\
\hline
\end{tabular}

Os índices de sementes quebradas foram baixos para todos os fatores estudados, concordando com MACHADO (2004), que relata que o grau de danificação da semente colhida se reduz sensivelmente, quando se utilizam máquinas equipadas com o sistema de trilha de fluxo axial. Tal fato deve-se ao maior período de tempo que o material permanece na seção de trilha, bem como devido a essa trilha não ser tão agressiva quanto a que ocorre no sistema tangencial. Portanto, máquinas dotadas com esse tipo de mecanismo são indicadas para a colheita de sementes de soja ou de grãos mais sensíveis a danificações mecânicas.

Segundo COSTA et al. (2001) e HERBEK \& BITZER (1997), rotações do cilindro de trilha inferiores a $500 \mathrm{rpm}$ promovem menores índices de danos à semente, ou seja, a operação acima de $500 \mathrm{rpm}$ torna-se prejudicial à qualidade das sementes. HERBEK \& BITZER (1997) enfatizam também que velocidades de operação na faixa de 4,0 a $5,0 \mathrm{~km} \mathrm{~h}^{-1}$ resultam em menores índices de perdas na colheita e, consequientemente, menores danos mecânicos e declínio no vigor.

\section{CONCLUSÕES}

As combinações de velocidade de operação $\left(3,5 ; 4,5\right.$ e $\left.5,5 \mathrm{~km} \mathrm{~h}^{-1}\right)$ e rotações do cilindro de trilha (400 e 500 rpm) não afetaram as variáveis vigor, impurezas, bandinha, emergência em areia e índice de velocidade de germinação.

O aumento da rotação de 400 para 500 rpm ocasionou aumento de sementes quebradas.

\section{REFERÊNCIAS}

BRASIL. Ministério da Agricultura e Reforma Agrária. Regras para análise de sementes. Brasília: SNAD/DNDV/CLAV, 1992. 365 p.

CORREIA, N.M.; REZENDE, P.M de. Manejo integrado de plantas daninhas na cultura da soja. Lavras: Editora UFLA, 2002. 55 p. (Boletim Agropecuário, 51)

COSTA, N.P.; MESQUITA, C.M.; MAURINA, A.C.; FRANÇA NETO, J.B.; PEREIRA, J.E.; BORDINGNON, J.R.; KRZYZONOWSKI, F.C.; HENNING, A. A. Efeito da colheita mecânica da 
soja nas características físicas, fisiológicas e químicas das sementes em três Estados do Brasil. Revista Brasileira de Sementes, v.23, n.1, p.140-5, 2001.

COSTA, N.P.; MESQUITA, C.M.; OLIVEIRA, M.C. Efeito da velocidade de deslocamento e do cilindro de trilha da colhedora sobre as perdas de sementes na colheita de soja. Informativo Abrates, Londrina, v.12, n.1-3, p.15-19, 2002.

COSTA, N.P.; MESQUITA, C.M.; MAURINA, A.C.; FRANÇA NETO, J.B.; KRZYZONOWSKI, F.C.; HENNING, A.A. Qualidade fisiológica, física e sanitária de sementes de soja produzidas no Brasil. Revista Brasileira de Sementes, v.23, n.1, p.128-32, 2003.

EMPRESA BRASILEIRA DE PESQUISA AGROPECUARIA. Tecnologias de produção de soja Paraná - 2005/EMBRAPA Soja. Londrina, 2005. 224 p. (Sistemas de Produção/EMBRAPA Soja, n.5).

FRANÇA NETO, J.B. Metodologia do teste de tetrazólio em sementes de soja. In: KRZYZANOWSKI, F.C.; VIEIRA, R.D.; FRANÇA NETO, J.B. (Ed.). Vigor de sementes: conceitos e testes. Londrina: ABRATES, 1999. p. 8.5-8.5 28.

HERBEK, J.H.; BITZER, M.J. Soybean production in Kentucky: harvesting, drying, storage and marketing. Lexington: University of Kentucky, College of Agriculture, 1997. part. 5, p.1-5.

MACHADO, A.L.T. Colhedoras de fluxo axial reduzem danos às sementes. Revista Seed News, v.2, n.4. Disponível em: <www.seednews.inf.br/portugues/seed74/artigocapa74.shtml>. Acesso em: nov. 2004

MAGUIRE, J.D. Speeds of germination-aid and evaluation for seedling emergence and vigor. Crop Science, Madison, v.2, n.2, p.176-7, 1962.

NAKAGAWA, J. Teste de vigor baseados no desempenho das plântulas. In: KRZYZANOWSKI, F.C.; VIEIRA, R.D.; FRANÇA NETO, J.B. (Ed.). Vigor de sementes: conceitos e testes. Londrina: ABRATES, 1999. p.2.1-2.6.

MOORE, R.P. Soybean germination. Seedsmen's Digest, San Antonio, v.11, n.3, p.12, 52, 54-55. 1960.

MOORE, R.P. Tetrazolium as a universally acceptable quality test of viable seed. Proceedings of the International Seed Testing Association, Copenhagen, v.27, n.3, p.795-805, 1962a.

MOORE, R.P. TZ checks your seed for quality. Crop Soil, Madison, v. 15, n.1, p. 10-2. 1962b.

MOORE, R.P. Tetrazolium staining for assessing seed quality. In: HEYDECKER, W. (Ed.) Seed ecology. London: Butterworth, 1973. p.347-66.

TOLEDO, F.F. de; MARCOS FILHO, J. Colheita de sementes. In: TOLEDO, F.F. de; MARCOS FILHO, J (Ed.). Manual das sementes: tecnologia da produção. São Paulo: Agronômica Ceres, 1977. p. 111-21. 